NASA Technical Memorandum 102091

\title{
Probabilistic Structural Analysis Methods of Hot Engine Structures
}

C.C. Chamis and D.A. Hopkins

Lewis Research Center

Cleveland, Ohio

Prepared for the

34th International Gas Turbine and Aeroengine Congress and Exposition sponsored by the American Society of Mechanical Engineers Toronto, Canada, June 4-8, 1989

\section{N/Sh}

(NA SA-TH-102091) PBOBABILISTIC STEUCTURAL ANALYSIS METHODS OF HOT ENGIAE STROCT OBES

(MaSA. Levis Research Center) 17 pCSCL $20 \mathrm{~K}$ 


\title{
PROBABILISTIC STRUCTURAL ANALYSIS METHODS OF HOT ENGINE STRUCTURES
}

\author{
C.C. Chamis and D.A. Hopkins \\ National Aeronautics and Space Administration \\ Lewis Research Center \\ Cleveland, Ohio 44135
}

\section{SUMMARY}

Development of probabilistic structural analys is methodology for hot engine structures is a major activity at NASA Lewis Research Center. It consists of three program elements: (1) composite load spectra methods, (2) probabilistic structural analysis methods, and (3) probabilistic analysis and structural reliability application. Recent progress includes: (1) quantification of the effects of uncertainties for several variables on high pressure fuel turbopump (HPFT) turbine blade temperature, pressure, and torque of the space shuttle main engine (SSME), (2) the evaluation of the cumulative distribution function for various structural response variables based on assumed uncertainties in primitive structural variables, and ( 3 ) evaluation of the failure probability. Collectively, the results demonstrate that the structural durability of hot engine structural components can be effectively evaluated in a formal probabilistic/reliability framework.

\section{INTRODUCTION}

It is becoming increasingly evident that deterministic structural analysis methods will not be sufficient to properly design critical components in hot engine structures. These structural components are subjected to a variety of complex, and severe cyclic loading conditions including high temperatures and high temperature gradients. Most of these are quantifiable only as best engineering estimates. These complex loading conditions subject the material to coupled nonlinear behavior which depends on stress, temperature, and time. Coupled nonlinear material behavior is nonuniform, is very difficult to determine experimentally, and perhaps impossible to describe deterministically. In addition, hot rotating structural components are relatively small. Fabrication tolerances on these components, which in essence are small thickness variations, can have significant effects on the component structural response. Fabrication tolerances by their very nature are statistical. Furthermore the attachment of components in the structural system generally differs by some indeterminant degree from that assumed for designing the component. In summary, all four fundamental aspects: (1) loading conditions, (2) material behavior, (3) geometric configuration, and (4) supports - on which structural analyses are based, are of a random nature. The direct way to formally account for all these uncertain aspects is to develop probabilistic structural analysis methods where all participating variables are described by appropriate probability functions.

NASA Lewis Research Center is currently developing probabilistic structural analysis methods for select engine structural components ( $f i g .1$ ). Briefly, the deterministic, three-dimensional, inelastic analys is methodology developed under the Hot Section Technology (HOST) and Research and Technology 
Base Programs is being augmented to accommodate the complex probabilistic loading spectra, the thermoviscoplastic material behavior, and the material degradation associated with the environment of aerospace propulsion system structural components. The goal of the methodology is to address the problem depicted schematically in figure 2 .

The development of probabilistic structural analysis methodology consists of the following program elements (ref. 1): (1) composite load spectra models, (2) computational probabilistic structural analysis methods, and (3) probabilistic analysis and structural reliability application. The development of the probabilistic structural analysis methodology is a joint program of NASA Lewis in-house and sponsored research. The objective of the proposed paper is to illustrate recent progress on the application of this methodology to determine the reliability of turbine blade components of rocket propulsion systems. Past progress of specific elements of the program are described in papers presented in several recent conferences (refs. 2 to 8 ). Recent activities have focused on extending the methods to include the combined uncertainties in several factors on the structural response (fig. 3). The objective of the present paper is to briefly describe recent progress in three program elements: composite load spectra models, probabilistic finite element structural analysis, and probabilistic strength degradation modeling. Progress is described in terms of fundamental concepts, computer code development, and representative numerical results.

\section{COMPOSITE LOAD SPECTRA}

The fundamental assumption for developing composite load spectra is that each individual load condition is the probabilistic time synthes is of four primitive parts: (1) steady state, (2) periodic, (3) random, and (4) spike. Each of these parts, except random, is described by a deterministic portion and a probabilistic perturbation about this deterministic portion as depicted schematically in figure 4. One justification for describing each loading condition in terms of primitive parts is that experts, over the years, have developed good judgments of the ranges of the perturbations about nominal (deterministic) conditions. The objective of the Composite Load Spectra program is to formalize the fundamental assumption in a computer code using: (1) available data from various rocket engines, (2) probability theory, and (3) a dedicated expert system.

A schematic diagram of the composite load spectra (CLS) computer code is shown in figure 5. Representative results obtained for the perturbations of different engine factors on the SSME high pressure fuel turbopump turbine blade are snown in figures 6 and 7 . Figure 6 depicts the nominal temperatures, while figure 7 indicates the temperature changes due to hot gas seal geometry and respective perturbations indicated in the figure caption. For example, the greatest temperature change due to gas seal geometry ( $\mathrm{fig}$. 7 ) is $53.3^{\circ} \mathrm{F}$. The combined contributions of this and other factors (not shown here) is $87.6^{\circ} \mathrm{F}$ which is in addition to the greatest nominal temperature of $1860^{\circ} \mathrm{F}$. Although at first glance a change of $87^{\circ} 6^{\circ} \mathrm{F}$ may seem insignificant, this is not the case, because at these levels, small temperature changes have dramatic effects on durability and cooling requirements. 
Another representative example is shown in figure 8 , where the effect of comparable factors on the torque of the high pressure oxidizer turbopump (HPOTP) are plotted as a function of time, for the start-up portion of a mission cycle. These bounds are substantially wider at some times then at others. Similar plots can be obtained for pressures or any other loading condition (ref. 5). The current CLS code permits the simultaneous perturbation of 47 different factors for each different load condition.

\section{PROBABILISTIC FINITE ELEMENi STRUCTURAL ANALYSIS}

The fundamental assumption for developing probabilistic finite element structural analysis (PFEM) is that the uncertainties in each primitive structural variable can be represented by an assumed probabilistic distribution. Primitive structural variables are those which are used to describe a structure such as: (1) stiffness, (2) strength, (3) thickness and tolerance, (4) spatial location, (5) attachment, and (6) various nonlinear dependencies (temperature, stress, time, etc.). A schematic of the probabilistic distributions for some primitive variables is shown in figure 9 . Subsequently, the uncertainties in the load conditions (described by the composite load spectra) and the uncertainties in the primitive structural variables are computationally simulated by performing probabilistic structural analyses to determine the random structural response of a specific SSME structural component. The structural response is generally described in terms of usual quantities such as displacement, frequencies, buckling loads, and structural fracture toughness. The integration is illustrated in figure 10.

It is instructive to compare component development by the traditional engineering approach and component evaluation using PFEM. The parallelism is summarized in table I. The former approach relies on physical experiments for quantification and requires that the material, fabrication process, and test methods be available. The latter approach is entirely computational and requires the integration of available structural analysis methods with available probability theory. The former approach has the advantage of demonstrating a specific technology while the latter has the advantage of assessing undeveloped, but with high payoff potential, candidate technologies. In addition, the former approach requires a large number of experiments to verify a design, while in the latter a design can be verified with strategically selected few experiments.

PFEM has been formalized and integrated into a computer code identified as numerical evaluation of stochastic structures under stress (NESSUS). A schematic diagram of NESSUS is shown in figure 11 . The user interacts with NESSUS through a dedicated expert system schematically shown in figure 12 (ref. 8). Representative results obtained using NESSUS are shown in figure 13. The distributions assumed for the primitive variables are listed in the table in figure 13. Both the individual and the combined effects of the primitive variable uncertainties on the combined stress (Von Mises) are shown in figure 13 in terms of cumulative distribution functions (CDF). The information generated during the PFEM can be used to establish the confidence level. A sample result is shown in figure 14 for one blade location. 
The curves in figure 14 can be used in a number of ways such as: (1) all the blades tested in the assumed conditions will have a mean combined stress between 57.9 and $62.1 \mathrm{ksi} 90$ percent of the time and (2) the combined stress in all the blades tested (under the assumed conditions) will range from 42 to $83 \mathrm{ksi}$. This indicates that a wide scatter in the combined stress is probable. Two implications that follow are: (1) assessing the durability/life of the blades using only material uncertainties will not be sufficient, and (2) obtaining wide scatter in measured stress/strain magnitudes does not necessarily indicate test procedure difficulties.

All the NESSUS results presented herein were obtained using about 1000 perturbations for each case studied. These perturbations are relatively small in number compared to direct Monte Carlo simulation which will normally require 20000 and greater simulations to generate the same curves (refs. 6 and 7 ). The reduced (but with comparable accuracy) number of simulations is a result of a NESSUS feature which utilizes the fast probability integration method (ref. 6) to select subsequent perturbations in a self-adaptive manner.

\section{PROBABILISTIC ANALYSIS FOR STRENGTH DEGRADATION}

The fundamental assumption for developing probabilistic analys is methods for strength degradation is that the uncertainties in the primitive variables affecting strength can be described by assumed distributions. Two different models are selected to demonstrate the concept. The models express the number of mechanical load cycles to failure. One of the models is based on linear elastic fracture mechanics and the other on a strength degradation model recently studied at NASA Lewis (ref. 9). The models with their respective primitive variables are summarized in table II.

Both of these models are used to predict the number of cycles to failure in a material typical for SSME components. The input for the fracture mechanics model is summarized in table III. The CDF obtained from this input is shown in figure 15. The input for the strength degradation model is summarized in table IV and the corresponding CDF is shown in figure 16. Both CDF's exhibit wide ranges for the probable number of cycles to failure. The linear fracture mechanics model shows a mean of 10000 cycles while the strength degradation model shows a mean of 10 million cycles. Based on this comparison the linear fracture mechanics model penalizes the material by three decades. It is important to note the differences between the two models: (1) the linear fracture mechanics model assumes the existence of a crack-like defect and then evaluates the number of cycles required to grow this defect to a critical size for imminent rapid propagation to fracture; (2) the strength degradation model does not presume the existence of defects and, therefore, includes both defect initiation and propagation resulting in greater number of cycles; (3) the linear fracture mechanics model has five primitive variables while the strength degradation model has 13 (assuming that the greater the number of primitive variables in the model the more inclusive the representation of the physics in the model, then the strength degradation model will be more accurate); and (4) The linear fracture mechanics model requires determination of $c$, $m$, and $a_{i}$ by specialized and often complex test methods while the strength degradation model uses available room temperature material properties. The computer code to perform both of these simulations is described in reference 9 . 


\section{CONCLUSIONS}

The development or probabilistic structural analysis methods for hot engine structures continues. Recent progress on its application to select SSME components includes: (1) the effects of the uncertainties of several factors on blade temperatures, pressures, and torque, (2) the evaluation of the cumulative distribution function of structural response variables based on assumed uncertainties in the structural primitive variables, (3) evaluation of failure probability, and (4) life assessment in terms of cumulative distribution function using linear fracture mechanics and strength degradation models. Three different computer codes are being developed in parallel: (1) Composite Load Spectra (CLS) for the probabilistic description of SSME component loads, (2) NESSUS, for the probabilistic structural analysis of select SSME structural components, and (3) a life durability code for the assessment of the fatigue cycles to failure of structural components in SSME mission environments. Collectively, the results obtained to date demonstrate that the structural durability of SSME critical components can be evaluated using the probabilistic methodology under development.

\section{REFERENCES}

1. Chamis, C.C., 1986, "Probabilistic Structural Analysis Methods for Space Propulsion System Components," NASA TM-88861.

2. Chamis, C.C. and Hopkins, D.A., Session Chairs, 1987, "Session IV, Structural Dynamics," Structural Integrity and Durability of Reusable Space Propulsion Systems, NASA CP-2471, pp. 117-200.

3. Liu, W.K., Besterfield, G.H., and Belytschko, T., 1987, "A Probabilistic Hu-Washizu Variational Principle," 28th Structures, Structural Dynamics and Materials Conference, Part 1, AIAA, New York, pp. 252-259.

4. Nagpal, V.K., Rubinstein, R., and Chamis, C.C., 1987, "Probabilistic Structural Analys is to Quantify Uncertainties Associated with Turbopump Blades," 28th Structures, Structural Dynamics and Materials Conference, Part 1, AIAA, New York, pp. 268-274.

5. Spencer, B.F. and Hopkins, D.A., 1988, "An Expert System for Probabilistic Description of Loads on Space Propulsion System Structural Components," 29 th Structures, Structural Dynamics and Materials Conference, Part 3, AIAA, New York, pp. 1262-1266.

6. Wu, Y.T. and Burnside, O.H., 1988, "Validation of the NESSUS Probabilistic Finite Element Analysis Computer Program," 29th Structures, Structural Dynamics and Materials Conference, Part 3, AIAA, New rork, pp. 1267-1274.

7. Shiao, M.C., Nagpal, V.K., and Chamis, C.C., 1988, "Probabilistic Structural Analysis of Aerospace Components Using NESSUS," 29 th Structures, Structural Dynamics and Materials Conference, part 3, AIAA, New York, pp. 1275-1282. 
8. Millwater, H., Palmer, K., and Fink, P., 1988, "NESSUS/Expert - An Expert System for Probabilistic Structural Analysis Methods, "29th Structures, Structural Dynamics and Materials Conference, Part 3, AIAA, New York, pp. 1283-1288.

9. Boyce, L. and Chamis, C.C., 1988, "Probabilistic Constitutive Relationships for Cyclic Material Strength Models," 29th Structures, Structural Dynamics and Materials Conference, Part 3, AIAA, New York, pp. 1299-1306.

TABLE I. - SOME HELPFUL PARALLELS

\begin{tabular}{|l|l|}
\hline $\begin{array}{l}\text { Traditional component development } \\
\text { Parameter identification } \\
\text { Characterization - database } \\
\text { Component fabrication }\end{array}$ & $\begin{array}{l}\text { PSAM component evaluation } \\
\text { Parameter identification } \\
\text { Probabilistic distributions } \\
\text { Component testing } \\
\text { Component test results database } \\
\text { Component analysis } \\
\text { Reliability/confidence level }\end{array}$ \\
\begin{tabular}{l|l} 
Component analysis results database \\
Reliability/confidence level
\end{tabular} \\
\hline Bhysical & Bottom line \\
\hline
\end{tabular}

TABLE II. - PROBABILISTIC ANALYSIS FOR MATERIAL STRENGTH OEGRADATION AND FRACTURE MODELS

1. Fatigue crack growth mode?

$$
\begin{aligned}
& N\left(a_{F}\right)=\left[\frac{1}{C \gamma^{m} n^{m / 2} \Delta \sigma^{m}}\right]\left[\frac{a_{F}^{-m / 2+1}-a_{i}^{-m / 2+1}}{-m / 2+1}\right] \text {, } \\
& \text { where } C, M, \Delta \sigma \text { and } a_{i} \text { are random variables }
\end{aligned}
$$

2. Strength reduction model

$$
N_{M}(S)=N_{M F}-\left\{N_{M F}-N_{M 0}\right)\left[\frac{S}{\left.S_{0}\left[\frac{T_{F}-T}{T_{F}-T_{0}}\right]^{n}\left[\frac{S_{F}-\sigma}{S_{F}-\sigma_{0}}\right]^{m}\right]^{1 / q}}\right\}
$$


TABLE III. - PRIMITIVE VARIABLE DISTRIBUTIONS FOR THE FATIGUE CRACK GROWTH MODEL

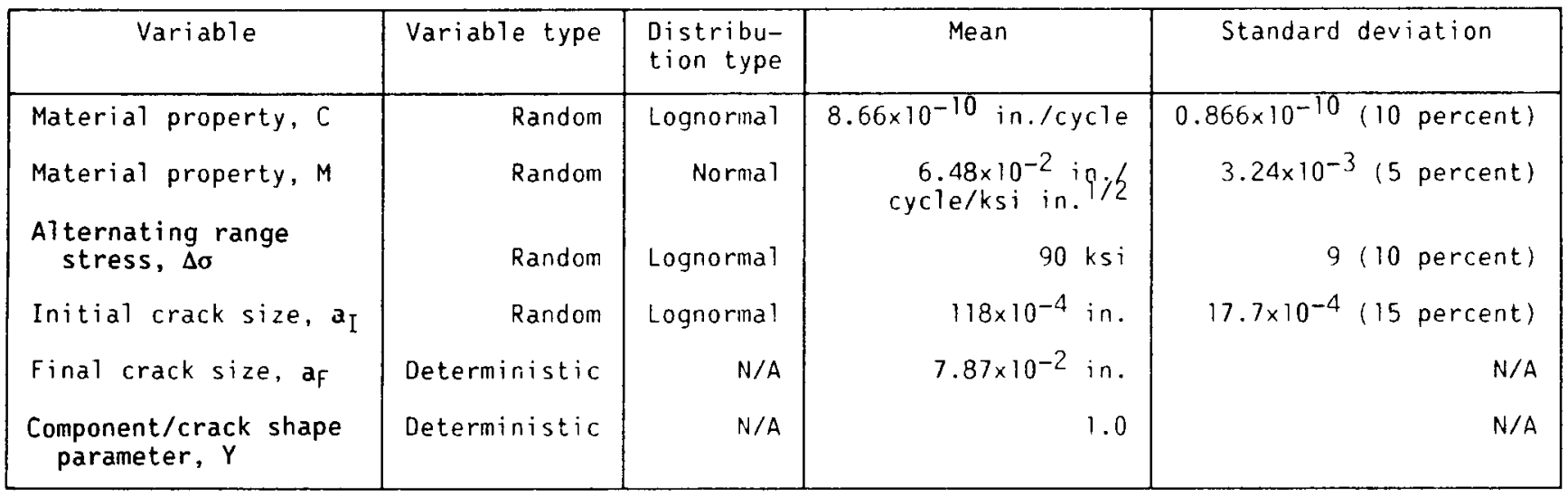

TABLE IV. - PRIMITIVE VARIABLE DISTRIBUTIONS FOR THE STRENGTH REDUCTION MODEL

\begin{tabular}{|c|c|c|c|c|}
\hline Variable & $\begin{array}{l}\text { Variable } \\
\text { Type }\end{array}$ & $\begin{array}{c}\text { Distribution } \\
\text { type }\end{array}$ & Mean & Standard deviation \\
\hline $\begin{array}{l}\text { Melting temperature, } T_{F} \\
\text { Ultimate tensile strength, } S_{F} \\
\text { Log of final cycle, } N_{M F} \\
\text { Reference temperature, TO } \\
\text { Residual compressive stress, o0 } \\
\text { Log of reference cycle, } N_{M O} \\
\text { Reference fatigue strength, } S_{0} \\
\text { Current temperature, T } \\
\text { Current mean stress, o } \\
\text { Current fatigue strength, } S \\
\text { Temperature exponent, } N \\
\text { Stress exponent, } M \\
\text { Cycle exponent, } Q\end{array}$ & Random & $\begin{array}{r}\text { Normal } \\
\text { Lognormal } \\
\text { Lognormal } \\
\text { Normal } \\
\text { Lognormal } \\
\text { Lognormal } \\
\text { Lognormal } \\
\text { Normal } \\
\text { Lognormal } \\
\text { Lognormal } \\
\text { Normal } \\
\text { Normal } \\
\text { Normal }\end{array}$ & $\begin{array}{r}2732 \text { of } \\
130 \mathrm{ksi} \\
8 \\
68 \text { of } \\
-2.9 \mathrm{ksi} \\
7 \\
72.6 \mathrm{ksi} \\
1562 \text { of } \\
21.8 \mathrm{ksi} \\
36.3 \mathrm{ksi} \\
0.5 \\
0.5 \\
0.5\end{array}$ & $\begin{array}{r}82.0(3 \text { percent }) \\
6.5(5 \text { percent }) \\
.8(10 \text { percent }) \\
2.0(3 \text { percent }) \\
-0.145(5 \text { percent }) \\
0.7(10 \text { percent }) \\
3.6(5 \text { percent }) \\
46.7(3 \text { percent }) \\
1.1(5 \text { percent }) \\
1.8(5 \text { percent }) \\
0.15(3 \text { percent }) \\
0.15(3 \text { percent }) \\
0.15(3 \text { percent })\end{array}$ \\
\hline
\end{tabular}




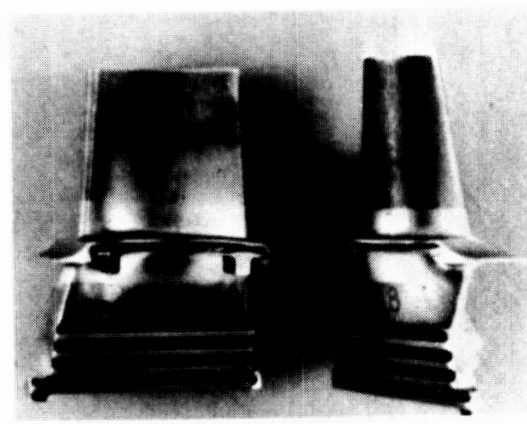

HIGH PRESSURE TURBOPUMP BLADE

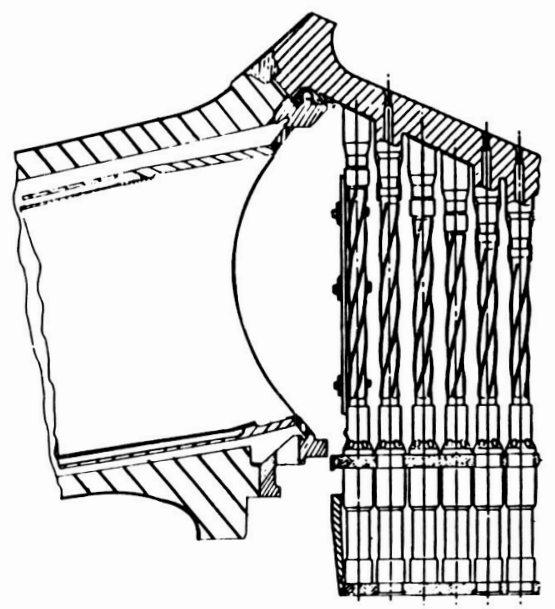

LOX POSTS

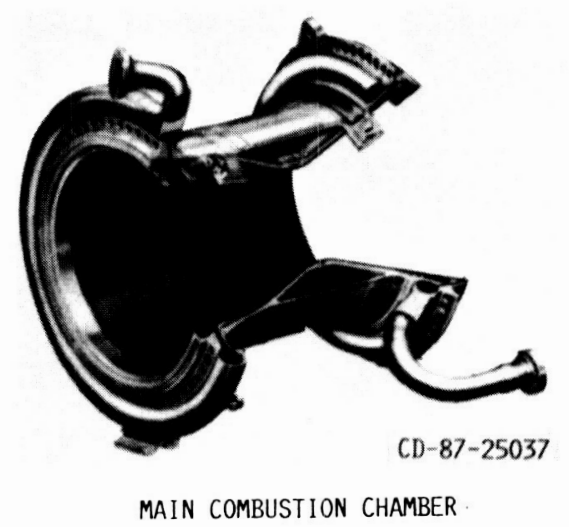

FIGURE 1. - SELECT SSME COMPONENTS INCLUDED IN THE PROBABLILISTIC STRUCTURAL ANALYSIS METHODS DEVELOPMENT PROGRAM. 
PROBLEM:

PROB $\left[\begin{array}{l}\text { NATURAL FREQUENCY } \\ \text { OF BLADE, } \mathbf{a}\end{array}<\begin{array}{l}\text { FREQUENCY } \\ \text { LIMIT, } \mathbf{a}_{\mathrm{L}}\end{array}\right]=$ ?

VARIABLES

- geometry

- STIFFNESS

- MASS

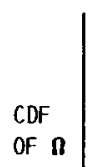

90\% CONFIDENCE BOUNDS?
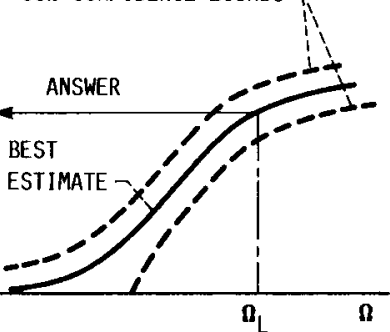

CONFIDENCE

- DIFFICULT ANALYSIS PROBLEM

- APPROXIMATE METHOD DEF INED

- USES NESSUS data base

- gives interval estimates - PROBABILITY

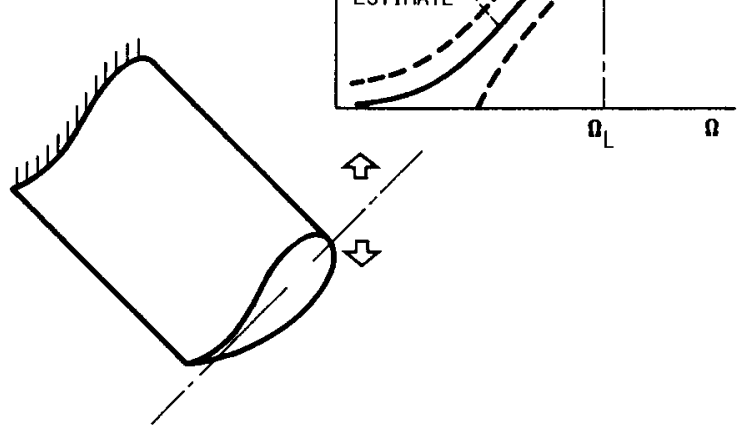

FIGURE 2. - PROBABILISTIC STRUCTURAL ANALYSIS DEFINITION.

PLANNED ACCOMPLISHMENT

DEVELOP PROBABILISTIC STRUCTURAL ANALYSIS METHODS/COMPUTER CODES FOR QUANTIFYING THE INDIVIDUAL AND COMBINED EFFECTS OF UNCER-

TAINTIES ON THE STRUCTURAL DURABILITY OF SSME COMPONENTS

COMBINED PROBABILITY OF OCCURRENCE

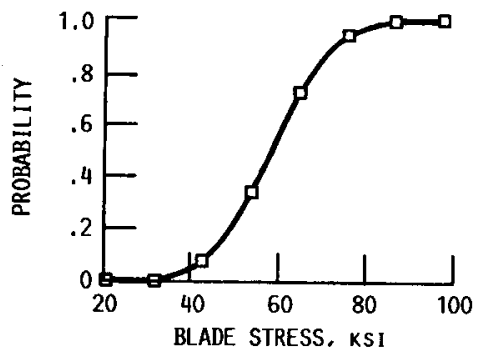

STATUS

- fORMUlated PROBABILISTIC FINITE ELEMENT METHODS

- deVEloped second generation COMPUTER CODE - OPERATIONAL AT LEWIS. UNCERTAINTIES INCLUDED:

- LOADS

- GEOMETRY

- MATERIAL

- SPATIAL POSITION

- ATTACHMENT

SIGNIF ICANCE

THE COMBINED PROBABILITY OF MAGNITUDE OF STRUCTURAL DURABILITY VARIABLES CAN BE DEIERMINED

FIGURE 3. - PROBABILISTIC STRUCTURAL ANALYSIS METHODS (PSAM). 


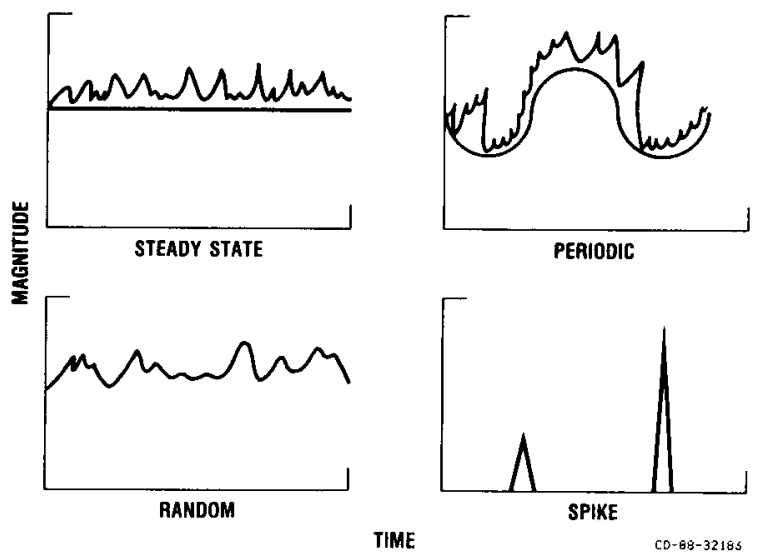

FIGURE 4. - EACH LOAD CONDITION IS THE PROBABILISTIC TIME SYNTHESIS OF FOUR PRIMITIVE PARTS: COMPOSITE LOAD SPECTRA.

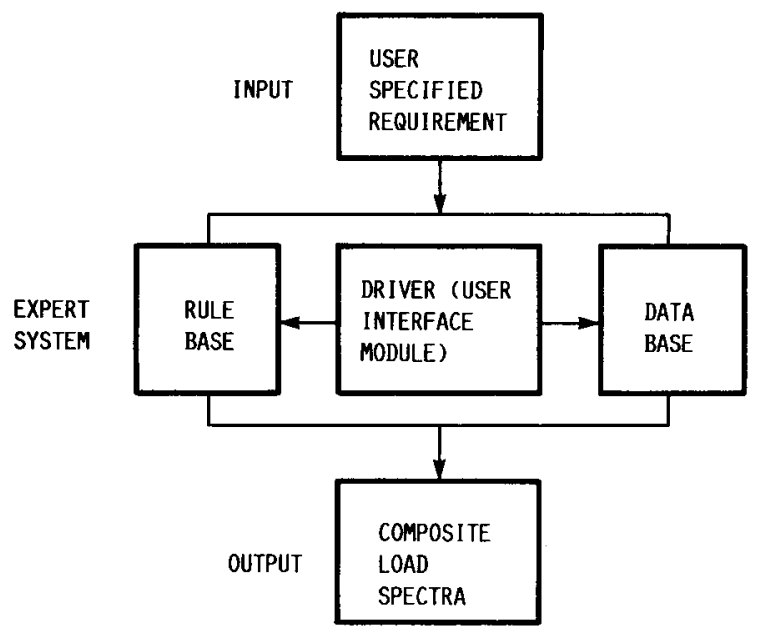

- RULE-BASE PRODUCTION SYSTEM

- IF-THEN RULES

- Simple INFERENCE SCHEME

- INFERENCE NET (DECISION TREE)

- Sophisticated pROBabilistic methods

- DISCRETE PROBABILITY DISTRIBUTION

- monte carlo

- BARRIER CROSSING

- poWERFUl KNOWLEDGe base

- INFLUENCE COEFFICIENTS

- scaling coefficients

- NOMINAL ENGINE COEFFICIENTS

- DUTY CYCLE LOAD PROFILES

- ENGINE CONFIGURATION AND GEOMETRY DATA

- RAW ENGiNe flight aND teSt DATA

FIGURE 5. - COMPOSITE LOAD SPECTRA SIMULATION USING EXPERT SYSTEMS. 


\section{ORIGINAL PAGE \\ BLACK AND WHITE PHOTCORARH}

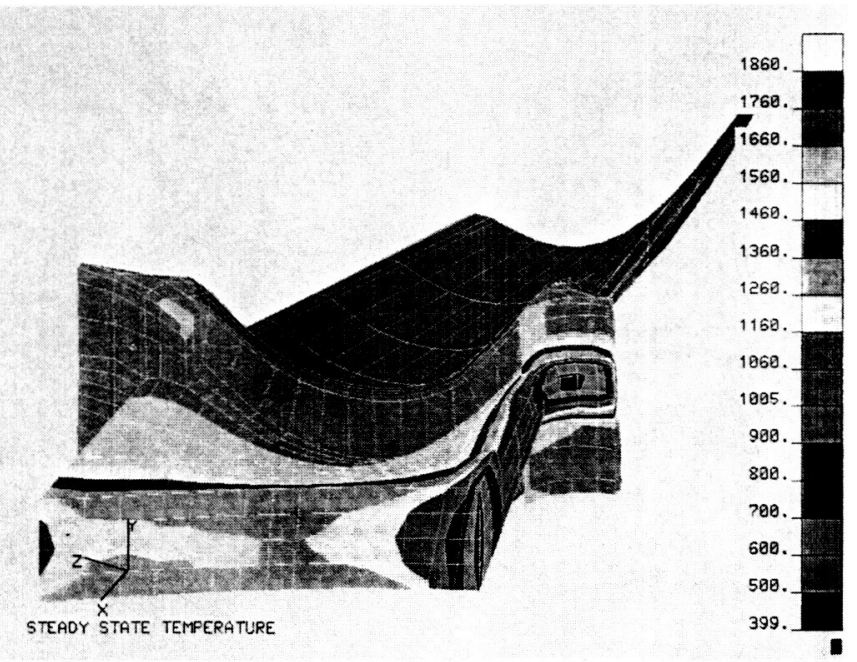

FIGURE 6. - COMPOSITE LOAD SPECTRA PREDICTED STEADY STATE TEMPERATURE.

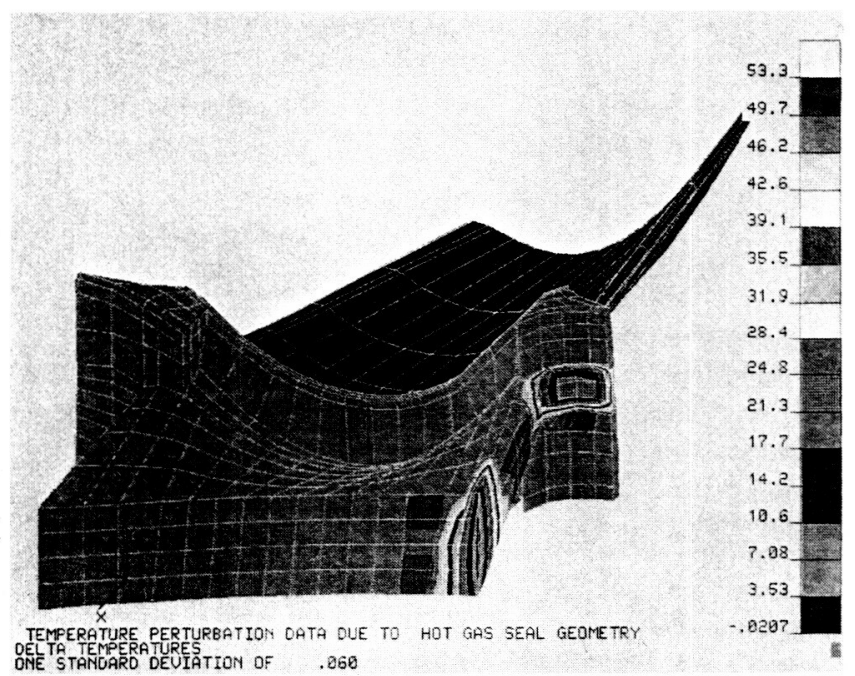

FIGURE 7. - TEMPERATURE PERTURBATION DATA DUE TO HOT GAS SEAL GEOMETRY DELTA TEMPERATURES. ONE STANDARD DEVIATION. 


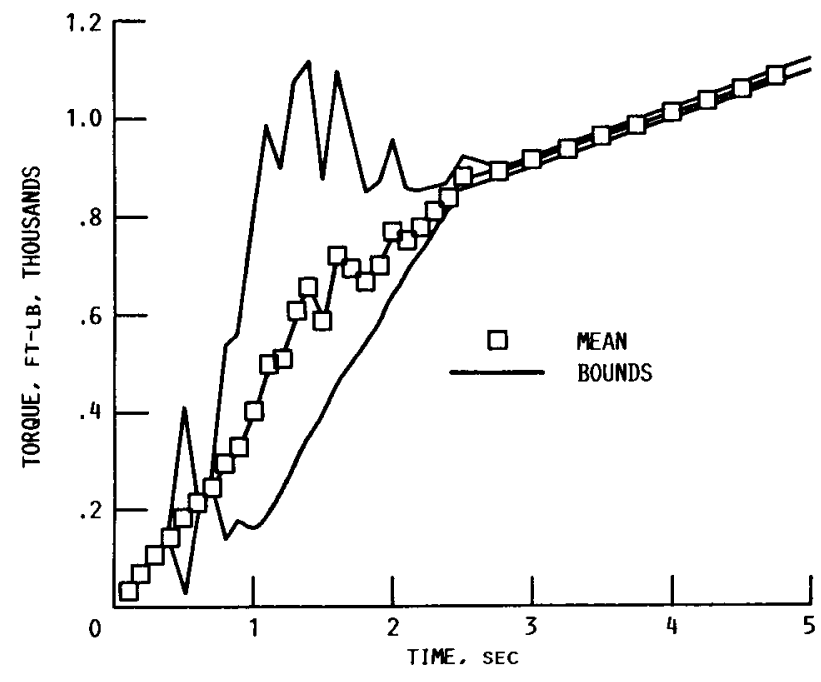

FIGURE 8. - TRANSIENT MODEL HPOTP TORQUE.
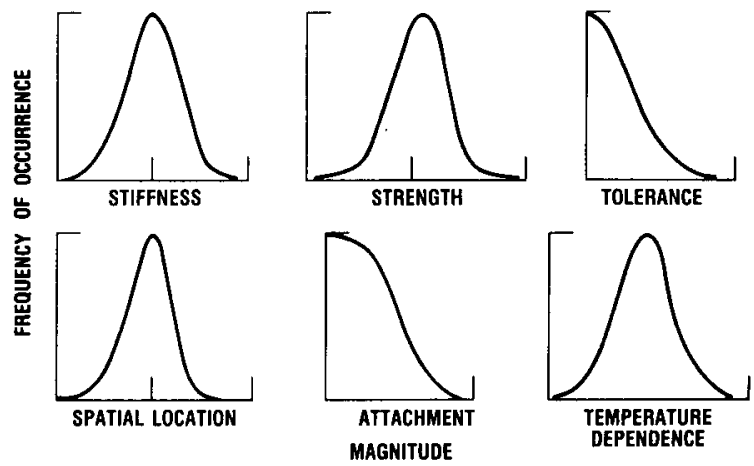

CD-98-32183 TAINTIES IN EACH STRUCTURAL PRIMITIVE VARIABLE CAN BE DESCRIBED BY ASSUMED CORRESPONDING PROBABILISTIC DISTRIBUTIONS.

GLOBAL: AT ALL NDDAL POINTS

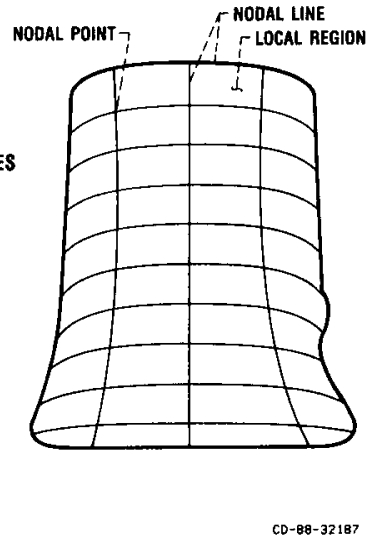

DETERMINED FROM THE RESULTS OF THE

MULTIPLE FINITE ELEMENT ANALYSES

CD-88-32187

FIGURE 10. - UNCERTAINTIES IN THE LOAD CONDITIONS AND STRUCTURAL PRIMITIVE VARIABLES ARE INTEGRATED BY PERFORMING MULTIPLE FINITE ELEMENT ANALYSES. 
<smiles>c1ccccc1</smiles><smiles>CC1C(C)C2CC1C2C</smiles>

PLANE STRESS<smiles>C12C3C4C1C1C2C3C41</smiles>

3D BRICK

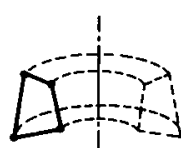

AXISYMMETRIC

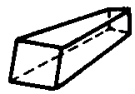

LINEAR BEAM

- all Elements INTEgRATED nUMERICALly

- linear lagrangian interpolating FUNCTIONS

- SELECTIVELY REDUCED INTEGRATION

(I)

TOPOLOGY

NODAL COORDINATES

NODAL SHELL THICKNESS

NODAL SHELL OR BEAM NORMALS

(II) GEOMETRIC PROPERTY

THICKNESS OF PLAIN STRESS ELEMENTS

ELASTIC BEAM SECTION PROPERTIES

(III) MATERIAL PROPERTY

ELASTICITY MODULUS

POISSON'S RATIO

THERMAL EXPANSION COEFFICIENT

MATERIAL DENSITY

(IV) BOUNDARY CONDITIONS

BASE SPRING STIFFNESSES

(V) LOADS

NODAL FORCE VECTORS

ELEMENT PRESSURES AND EDGE

TRACTIONS

NODAL TEMPERATURES

FIGURE 11. - PROBABILISTIC FINITE ELEMENT COMPUTER CODE NESSUS.

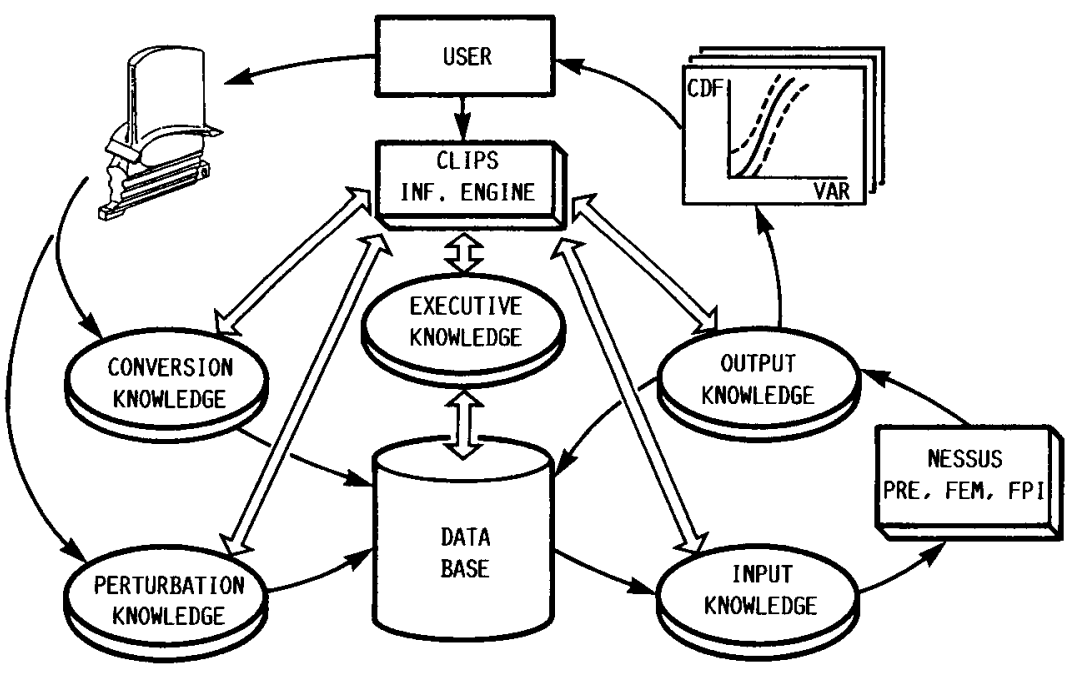

FIGURE 12. - MESSUS DEDICATED EXPERT SYSTEM. 
RANDOM VARIABLE DISTRIBUTION TABLE

\begin{tabular}{|c|c|c|}
\hline CASE & $\begin{array}{c}\text { RANDOM } \\
\text { VARIABLE, } \\
\text { RV }\end{array}$ & ${ }^{a} \mathrm{COV}$ OF RV \\
\hline 1 & $X-\operatorname{COOR}(N)^{b}$ & $0.005(\text { STD })^{C}$ \\
\hline 2 & $Y-\operatorname{COOR}(\mathrm{N})$ & .005 (STD) \\
\hline 3 & $Z-\operatorname{COOR}(\mathrm{N})$ & .005 (STD) \\
\hline 4 & $T$ - TEMP (N) & $60^{\circ} \mathrm{F}$ (STD) \\
\hline 5 & $\begin{array}{l}E-\text { YOUNG'S } \\
\text { MODULUS (N) }\end{array}$ & 0.10 \\
\hline 6 & $\begin{array}{l}L \text { - LATERAL } \\
\text { PRESSURE (N) }\end{array}$ & 0.20 \\
\hline 7 & $\begin{array}{l}F-\text { CONC. } \\
\text { LOAD (N) }\end{array}$ & 0.20 \\
\hline 8 & $\begin{array}{c}\text { R - ROTATION } \\
\text { SPEED (N) }\end{array}$ & 0.02 \\
\hline 9 & $c$ - COMBINE & \\
\hline
\end{tabular}

CDF OF VON MISES STRESS DUE TO SINGLE/ COMBINED RANDOM VARIABLE PERTURBATION

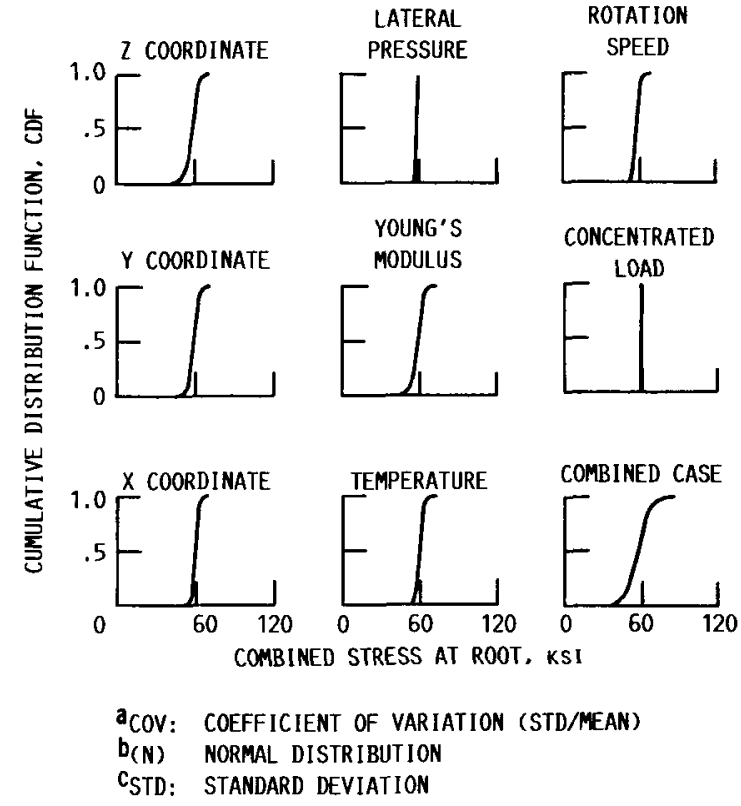

FIGURE 13. - PROBABILISTIC STRUCTURAL ANALYSIS USING NESSUS.

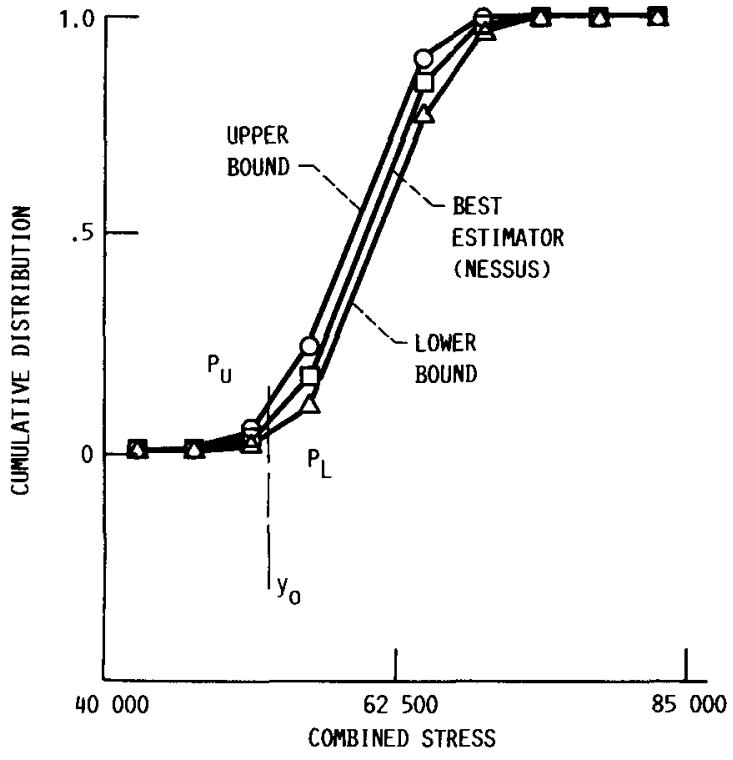

FIGURE 14. - 90\% CONFIDENCE BOUND RESULT FROM UNCERTAINTY IN THE INPUT PARAMETERS. 


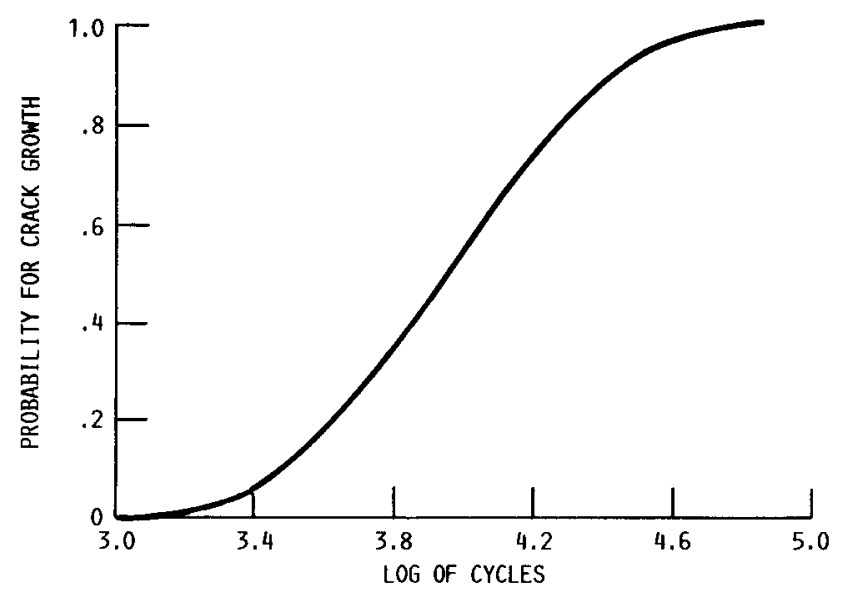

FIGURE 15. - SIMULATED FAIL URE PROBABILITY USING A FATIGUE CRACK GROWTH MODEL.

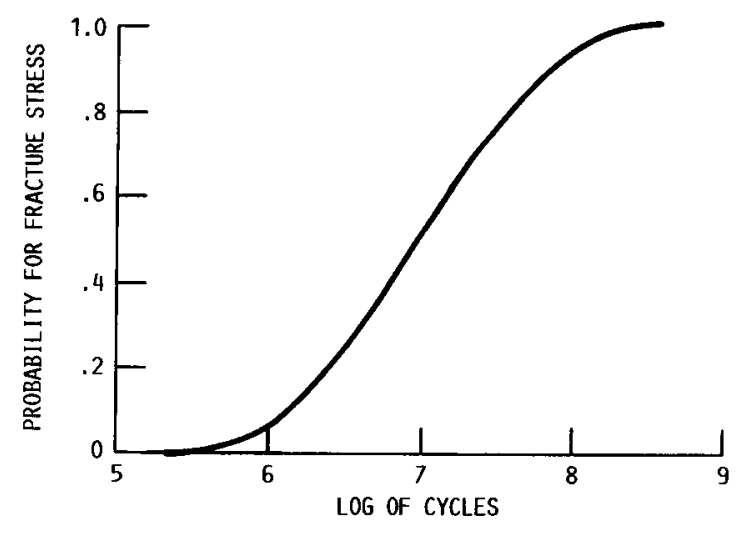

FIGURE 16. - SIMULATED FAILURE PROBABILITY USING A STRENGTH REDUCTION MODEL. 


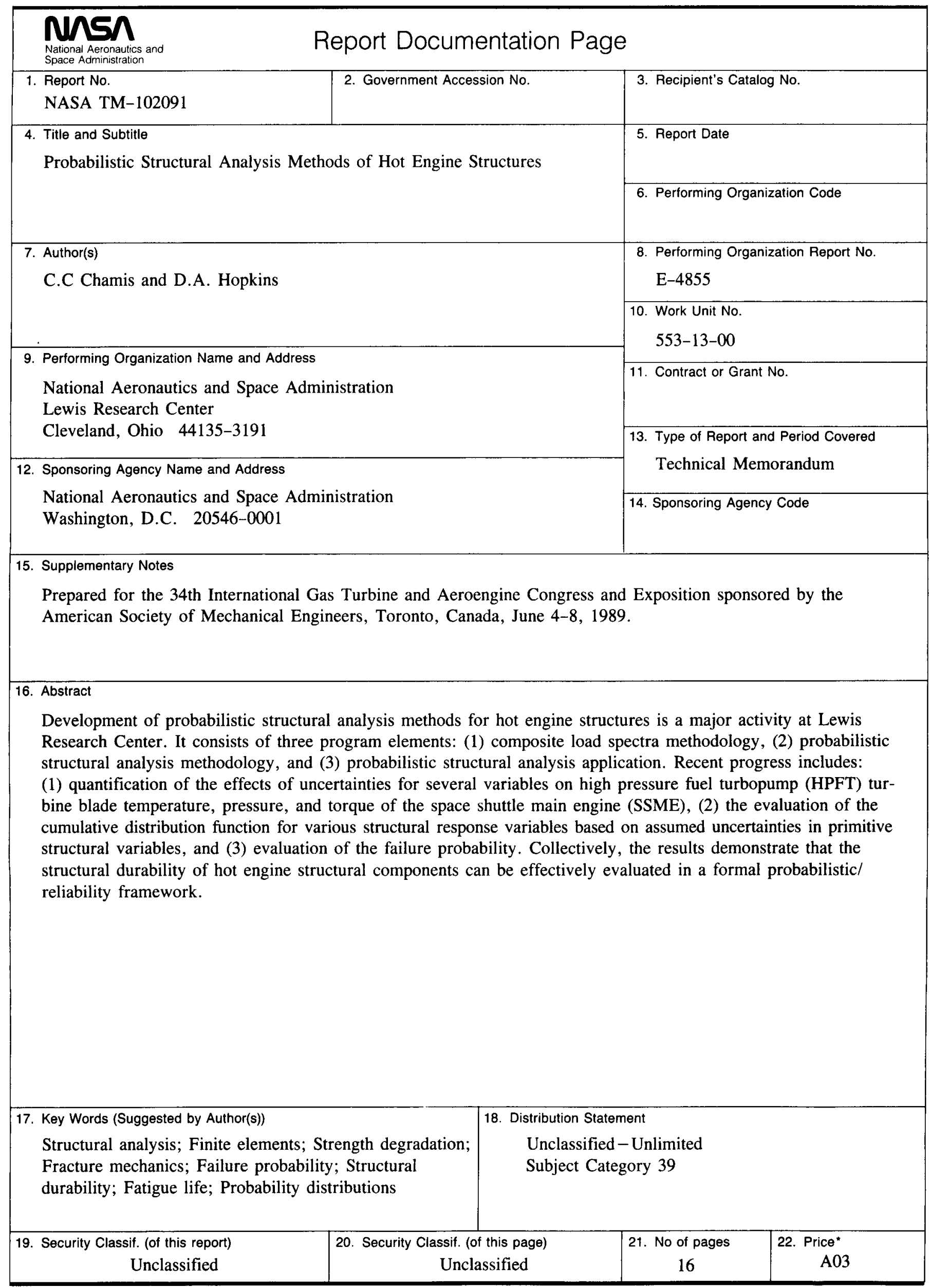

